\title{
The storm-time ring current: a statistical analysis at two widely separated low-latitude stations
}

\author{
P. Francia ${ }^{1,2}$, U. Villante ${ }^{1,2}$, N. Adorante ${ }^{2}$, and W. D. Gonzalez ${ }^{3}$ \\ ${ }^{1}$ Dipartimento di Fisica, Università, L'Aquila, Italy \\ ${ }^{2}$ Consorzio Area di Ricerca in Astrogeofisica, L'Aquila, Italy \\ ${ }^{3}$ Instituto de Pesquisas Especiais, Sao José dos Campos, Sao Paulo, Brazil
}

Received: 3 December 2003 - Revised: 1 July 2004 - Accepted: 15 August 2004 - Published: 3 November 2004

\begin{abstract}
We conducted a statistical analysis of the geomagnetic field variations during the storm main phase at two low-latitude stations, separated by several hours in magnetic local time, in order to investigate the asymmetry and longitudinal extent of the storm-time ring current. The results show evidence for an asymmetric current which typically extends from evening to noon and, during moderate solar wind electric field conditions, up to the early morning, confirming the important role of the magnetospheric convection in the ring current energization. We also analyzed a possible relationship between the local current intensity during the storm main phase and the substorm activity observed at different time delays $\tau$ with respect to the storm onset. The results show a significant anticorrelation for $\tau=-1 \mathrm{~h}$, indicating that if the substorm activity is high just before the storm, a weaker ring current develops.
\end{abstract}

Key words. Magnetospheric physics (solar windmagnetosphere interactions; storms and substorms; magnetospheric configuration and dynamics)

\section{Introduction}

A growing interest about the relative importance of the symmetric and asymmetric component of the storm-time ring current has been recently documented in the study of the development and decay of geomagnetic storms (e.g. Grafe, 1999). As is well known, the use of the $D_{s t}$ index, i.e. the simple average of the horizontal geomagnetic field $H$ component (corrected both for the $S q$ effects and dipole latitude) at four not uniformly spaced low-to mid-latitude stations, is based on the general assumption of a symmetric equatorial ring current. However, the existence of a partial storm-time ring current has been proposed since the 1960s; for example, Cummings (1966) found that, at two $D_{s t}$ stations, the occurrence of local disturbances with $H$-values

Correspondence to: P. Francia

(patrizia.francia@aquila.infn.it)
$<-100 \mathrm{nT}$, was maximum at $\sim 18: 00 \mathrm{LT}$. Later on, several works showed that, during the storm main phase, the geomagnetic field depression in the afternoon side was deeper than in the morning side; this feature was also observed in the magnetosphere, indicating a magnetospheric origin of this asymmetry (Frank, 1967; Cahill, 1970; Siscoe and Crooker, 1974). More recently, both experimental studies and theoretical models confirmed the large LT asymmetry in the stormtime ring current (Roelof, 1987; Hamilton et al., 1988; Grafe, 1999; Takahashi et al., 1990; Liemohn et al., 1999).

It is now generally accepted that the enhanced magnetospheric convection caused by a long lasting, strong southward interplanetary magnetic field (IMF) component has a central role in the intensification of the ring current (Gonzalez et al., 1994; Tsurutani and Gonzalez, 1997); indeed, the cross-tail convection electric field, which is proportional to the eastward solar wind (SW) electric field, drives ions, mainly from the plasma sheet, into the inner magnetosphere, causing the westward ring current to grow significantly. In this context, Liemohn et al. (2001) studied the contributions from the symmetric and asymmetric component of the ring current to the storm-time corrected $D_{s t}{ }^{*}$ index (i.e. removing the effects of the magnetopause currents and induced currents in the conducting Earth). They clearly showed that, during the main and early recovery phase, ions flow along open trajectories in the dusk and afternoon sectors before encountering the dayside magnetopause and then produce a highly asymmetric ring current. In the late recovery phase, when the convection electric field diminishes, particle paths convert from open to closed, forming a symmetric ring that dominates the $D_{s t} *$ contribution.

On the other hand, the storm-time ring current also depends on the density of the plasma sheet ions, which represent the major source population (Daglis and Kozyra, 2002): indeed, a clear relationship has been observed between the inner plasma sheet density and the $D_{s t} *$ minimum value (Thomsen et al., 1998; Kozyra et al., 1998). Moreover, since plasma sheet density enhancements are strongly related to high SW densities, with time lags of $4-5 \mathrm{~h}$ (Borovsky et al., 
1997 ; 1998), the ring current intensity might be expected to be also related to the SW density. However, while Smith et al. (1999) demonstrated, using a few years of data, that both the SW electric field and density give significant and independent contributions to the strength of the ring current, a similar and more extended analysis by O'Brien and McPherron (2000a) did not confirm such correlation. More recently, Kozyra (2001), analyzing the development of three magnetic storms, found that plasma sheet density drops significantly limited the energy input in the inner magnetosphere, even in the presence of a strong southward IMF component; she pointed out that such density drops just followed the occurrence of a major substorm in each of the three cases.

In the present study we focused our attention on the estimate of the asymmetry and longitudinal extent of the stormtime ring current. For this scope, we made a comparison between locally occurring disturbances and the $D_{s t}$ index, which roughly represents the longitudinal average of disturbances, during the main phase of a large set of storms. In this sense, we used the $H$-measurements at two stations which are approximately located at the same latitudes as $D_{s t}$ stations, but not involved in the $D_{s t}$ index computation; their wide longitudinal separation allows one to observe the geomagnetic perturbations associated with the same storm at different local times. The analysis shows evidence for an asymmetric ring current which generally extends from evening to noon and, during moderate SW electric field conditions, up to the local morning. In addition, on the basis of the Kozyra (2001) results, we analyzed the possible relationship between the local storm-time ring current intensity and the substorm activity at different time delays $\tau$ with respect to the storm onset and found a significant anticorrelation for $\tau=-1 \mathrm{~h}$.

\section{Data and analysis}

We used the 1-h averages of $H$-measured during 1998-2001 at L'Aquila (AQU, Italy, IGRF99 corrected geomagnetic latitude $36.3^{\circ} \mathrm{N}$; MLT=UT+1:37) and Memambetsu (MMB, Japan, $37^{\circ} \mathrm{N}$; MLT=UT+9:07). The interplanetary data are from Wind spacecraft.

We examined time intervals characterized by a SW eastward electric field $E_{y}>5 \mathrm{mV} / \mathrm{m}$ for at least $3 \mathrm{~h}$ and selected 20 events; they were associated to geomagnetic storms with $D_{s t}$ minimum value $\leq-100 \mathrm{nT}$ (Tsurutani and Gonzalez, 1997). For these events, we computed the $D_{s t} *$ index using the formula $D_{s t} *=D_{s t}-\mathrm{b}(p)^{1 / 2}+\mathrm{c}$, (where $p$, the $\mathrm{SW}$ dynamic pressure, is given in $\mathrm{nPa}, \mathrm{b}=7.26 \mathrm{nT} /(\mathrm{nPa})^{1 / 2}$ and $\mathrm{c}=11 \mathrm{nT}$; O'Brian and McPherron, 2000b). The hourly averages of $H$ at the two stations were corrected $\left(H^{*}\right)$ for the diurnal variation (obtained from the average on the five quietest days in the month), the dipole latitude and the magnetopause current effects.

Figure 1 shows the diurnal pattern of $H^{*}$ at AQU a) and MMB b) for the selected storms; in this figure arrows mark the onset of the main phase as identified from the $D_{s t} *$ in- dex. On average, an afternoon/morning asymmetry emerges at both stations: in general, indeed, when the storm onset occurs in the postmidnight and early morning sector, $H^{*}$ shows a moderate or negligible decrease; on the contrary, when it occurs around local noon and in the afternoon, $H^{*}$ is strongly perturbed. As a consequence, different geomagnetic disturbances are observed at the two stations for the same event. For example, at the onset of storms \# 1, 9, 11, 17 and 19, the field at AQU, in the local evening, shows a clear depression, while at MMB, in the postmidnight hours, it is almost undisturbed; on the other side, the development of the storms \# 4, $6,7,8,10$, and 13 , which is clearly observed at MMB just before local noon, is not simultaneously detected at AQU in the postmidnight/early morning.

These results suggest that, in general, the ring current is not uniformly distributed in longitude during the storm main phase. In order to better investigate this aspect, we considered the hourly values of $H^{*}$ and $D_{s t} *$ during a 3-h interval following the storm onset, and, assuming a linear relationship between these quantities $\left(H^{*}=R^{*} D_{s t} *\right.$, we evaluated the slope $R$. In this sense, $R$-values can be considered a measurement of the local field perturbation with respect to the average.

Mainly in the nightside, additional currents (field-aligned and ionospheric closure currents, or magnetotail currents) may contribute significantly to the storm time $H^{*}$ variations (Greenspan and Hamilton, 2000, and references therein; Skoug et al., 2003); consistently, we excluded from our analysis the 3-h intervals between 21:00-02:00 MLT when the ring current intensification could not be the dominant cause for the local field variations.

Figure 2 shows the MLT dependence of the estimated $R$ values. As can be seen, $R$ tends to increase from values $<1$ during the local morning to values $>1$ in the afternoon, indicating a less (more) intense ground disturbance in the local morning (afternoon) with respect to the average. This behaviour confirms the asymmetry of the ring current which extends mainly in the postnoon magnetosphere. In this sense, our results are consistent with the conclusions drawn by Liemohn et al. (2001), who found a dominant asymmetric component in the main phase. We also found it useful to sort the events according to the average value of the SW electric field $E_{y}$ in the corresponding 3-h interval: events with $E_{y}$ exceeding the overall average value $(8 \mathrm{mV} / \mathrm{m})$ are indicated by stars, the others by dots. As can be seen, $R$-values corresponding to moderate $E_{y}$ are typically higher than $R$-values corresponding to strong $E_{y}$, at least up to 16:00 MLT (unfortunately, the lack of intervals characterized by strong $E_{y}$ does not allow one to draw a similar conclusion in the evening sector). In particular, we note that, during moderate $E_{y}$ conditions, $R>1$ values also occur in the local morning; indeed, the 09:00-13:00 MLT sector seems to correspond to a transition region where both intervals with $R>1$ and $R<1$ can be observed depending on the $E_{y}$ value. In order to investigate this aspect, we compared $R$ and the corresponding $E_{y}$ values for the intervals between 09:00-13:00 MLT (Fig. 3). The experimental results show that, for $E_{y} \geq 8 \mathrm{mV} / \mathrm{m}$, a rela- 

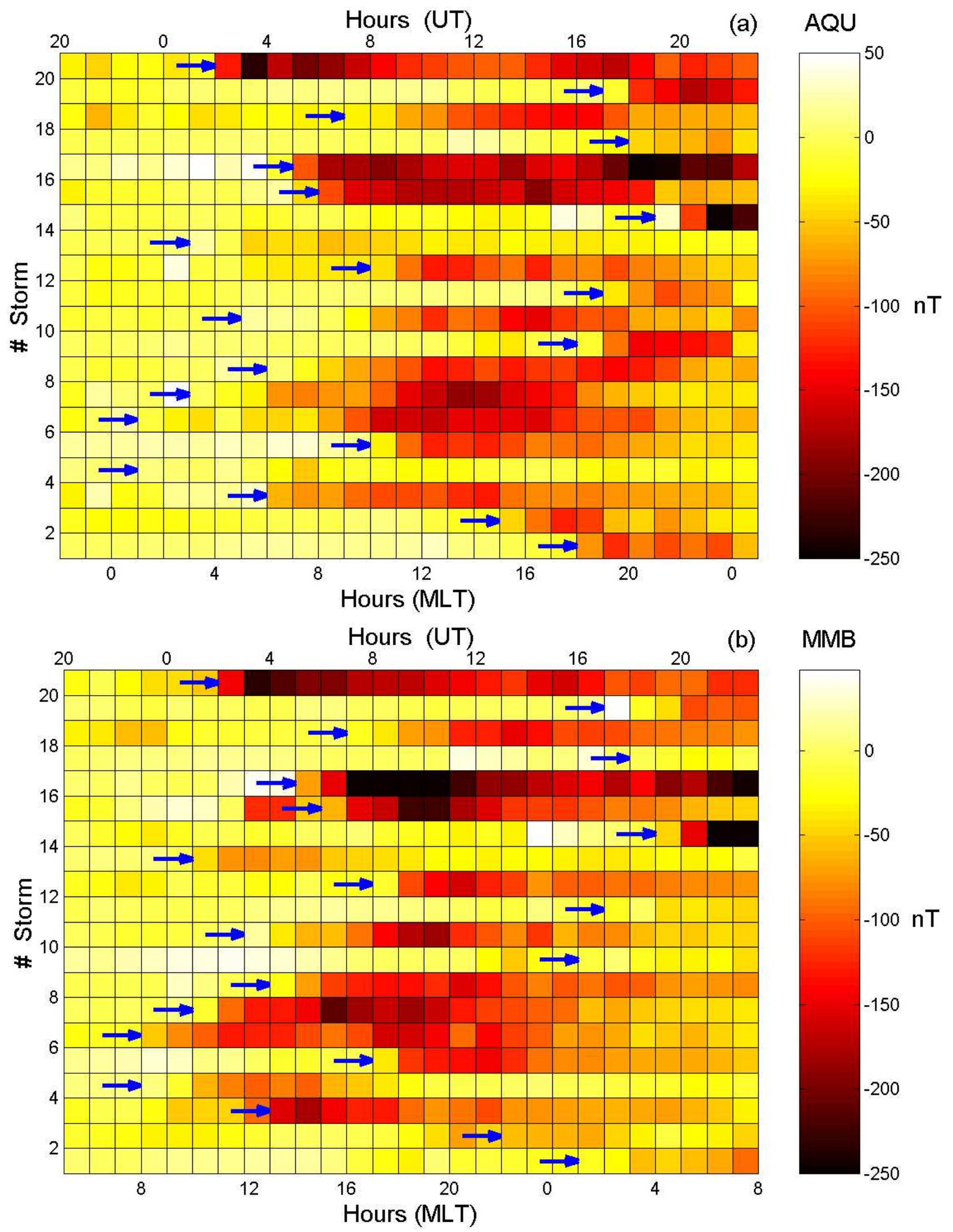

Fig. 1. The diurnal pattern of the $H^{*}$ hourly values at AQU (a) and MMB (b) for the selected events. Arrows mark the onset of each storm as observed from the $D_{s t}$ index. 


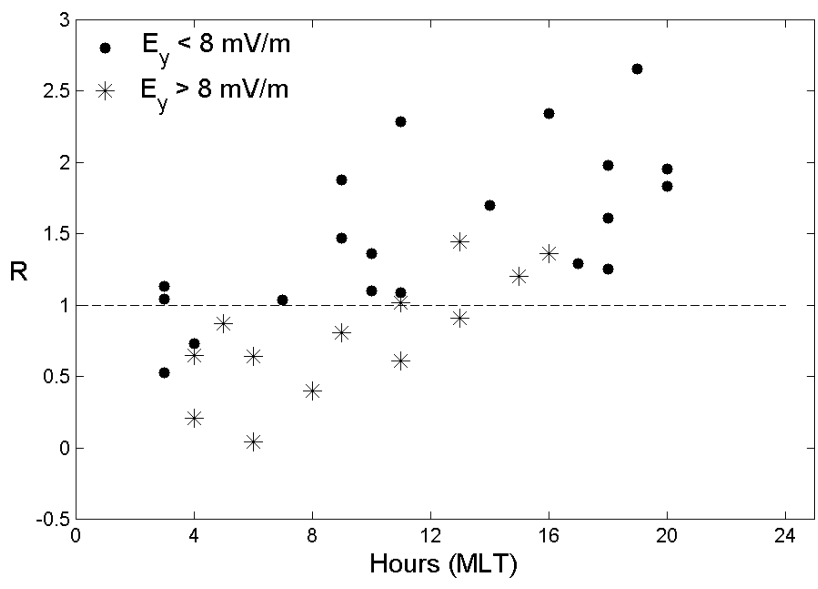

Fig. 2. The MLT dependence of the $R$ ratio sorting the intervals according to the SW electric field.

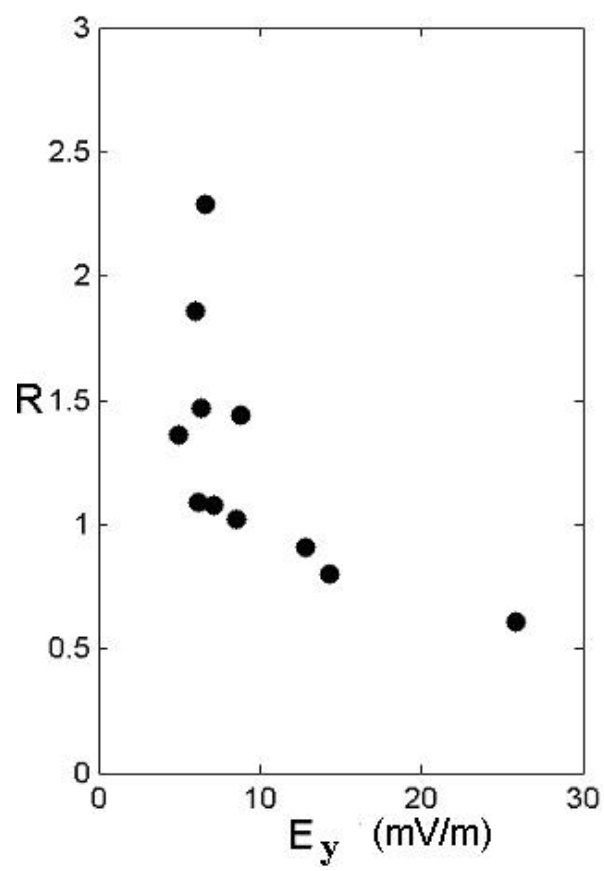

Fig. 3. The $R$ ratio versus the SW electric field for 09:0013:00 MLT intervals.

tionship emerges between the two parameters which reveals that strong electric fields play a major role in the inhibition of the storm-time current in this time sector, and then in determining its longitudinal extension. This suggests that during higher $E_{y}$ conditions, most of the highly energized ions flow out through the postnoon magnetopause and the consequent weak current causes negligible field disturbances in the prenoon hours. On the other hand, moderate $E_{y}$ would drive ions on more closed trajectories with a consequent current intensification in the 09:00-13:00 MLT sector.

As an example, in Fig. 4 we show in detail one of the two events for which, around 09:00 MLT at MMB, a $R>1$ value is observed. The storm started on 25 June 1998 between

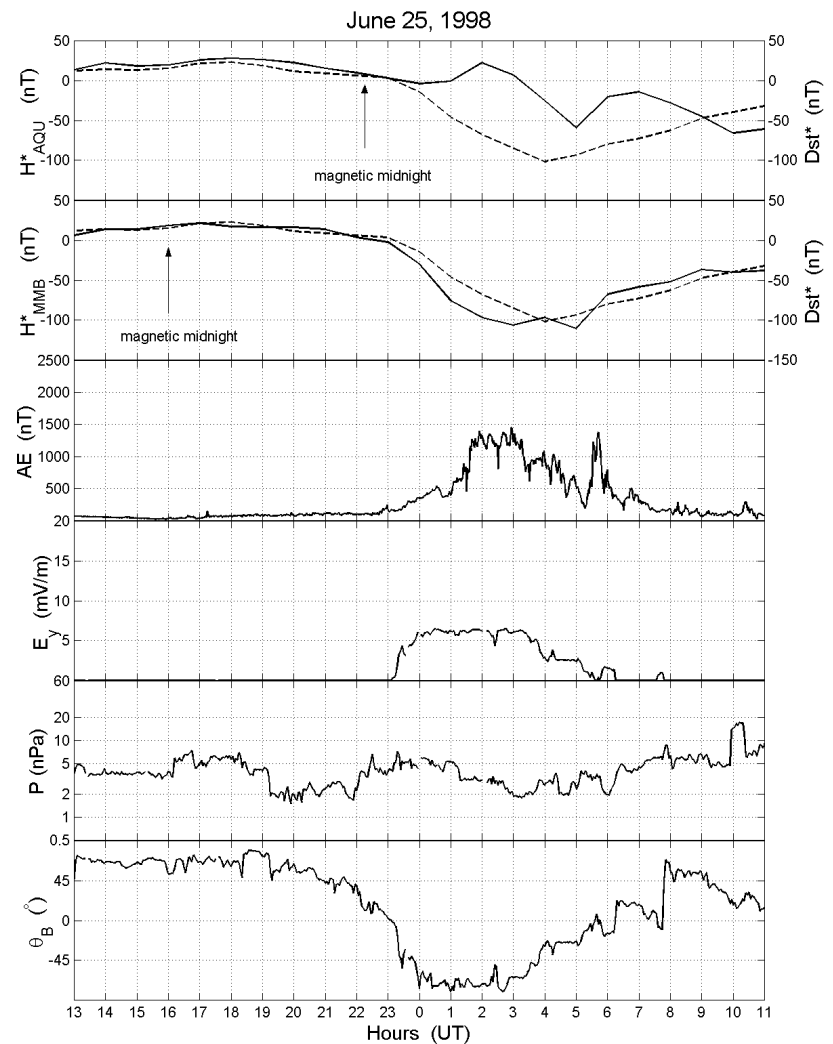

Fig. 4. From top to bottom the hourly values of the $H^{*}$ component at AQU and MMB (solid line) and the $D_{s t} *$ index (dashed line), the $\mathrm{AE}$ index, the dawn-dusk solar wind electric field, the solar wind dynamic pressure and the interplanetary magnetic field $\theta$ angle for the 25 June 1998 event.

23:00-24:00 UT; the IMF turned southward at $~ 23: 00$ UT and a moderate $E_{y}(\sim 6 \mathrm{mV} / \mathrm{m})$ occurred in the following $3 \mathrm{~h}$. While $H^{*}$ does not show any decrease at AQU, in the postmidnight hours, the storm is clearly observed at MMB around 09:00 MLT and is characterized by a field decrease steeper than the average $(R=1.9)$, indicating a strong local current.

For comparison, we show in Fig. 5 the $R<1$ event observed around 09:00 MLT at AQU; the storm occurred on 12 August 2000 (a typical two-step storm). The first storm intensification $(\sim 03: 00$ UT) corresponds to a $\sim 1.5$-h interval characterized by an average $E_{y} \sim 7.45 \mathrm{mV} / \mathrm{m}$ : it is observed at MMB (around local noon) but not at AQU (in the early morning). The second intensification, which is the one considered in our statistical analysis, is due to the IMF southward turning detected at 05:30 UT and is associated with a long duration $(>4 \mathrm{~h}) E_{y}$ with an high average value $(\sim 14.3 \mathrm{mV} / \mathrm{m})$. Correspondently, at MMB the first recovery abruptly ends and in the time interval 06:00-09:00 UT (around 16:00 MLT) a strong decrease of the field due to the further intensification of the ring current is observed $(R=1.4)$; at AQU (around 09:00 MLT) the field decrease is less pronounced $(R=0.8)$, indicating a weaker current in the local morning. 


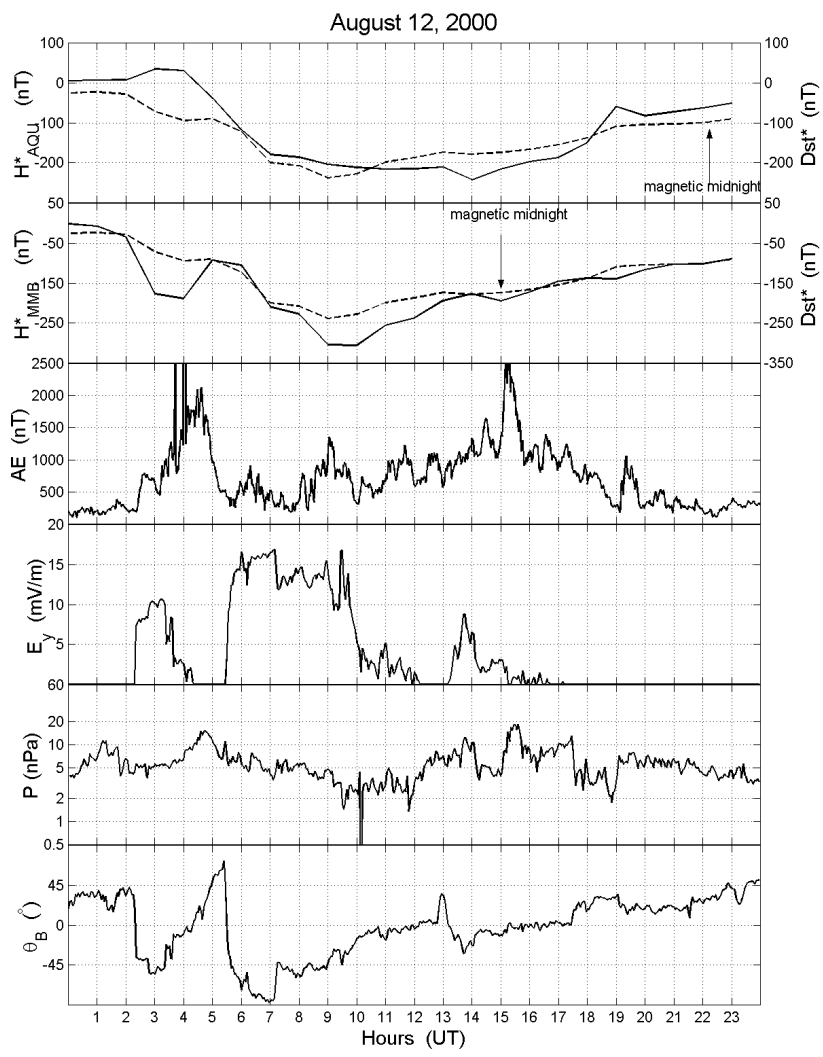

Fig. 5. From top to bottom the hourly values of the $H^{*}$ component at AQU and MMB (solid line) and the $D_{s t} *$ index (dashed line), the $\mathrm{AE}$ index, the dawn-dusk solar wind electric field, the solar wind dynamic pressure and the interplanetary magnetic field $\theta$ angle for the 12 August 2000 event.

Another important element for the storm-time ring current formation is represented by the density of the plasma sheet, which can be strongly variable depending on SW or magnetospheric conditions. On the basis of the Kozyra (2001) results, which relate the plasma sheet density variations to the substorm occurrence, we explored the possible relationship between the local current intensity during the storm main phase and the substorm activity observed at different time delays with respect to the storm onset. To this purpose, we computed the correlation coefficient $\rho$ between the $R$-values and 1-h averages of the AE index, assuming it as a proxy of the substorm activity. Table 1 shows the results obtained for AE averaged over 1 hour for different time delays $\tau(\tau=0$ corresponds to the storm onset). The best $\rho$ (above the $99 \%$ confidence limit) is found for $\tau=-1 \mathrm{~h}$ and is negative, suggesting a possible anticorrelation of $R$ with the substorm activity occurring just before the storm. This relationship is evidenced in Fig. 6a, where the $R$-values are plotted as a function of the AE index averaged over the hour preceding the storm onset. Moreover, since our previous results suggest that the storm-time current is generally located in the afternoon sector, more definitely during high $E_{y}$ conditions, we restricted our analysis to afternoon intervals during high $E_{y}$ conditions and found that the correlation coefficient still
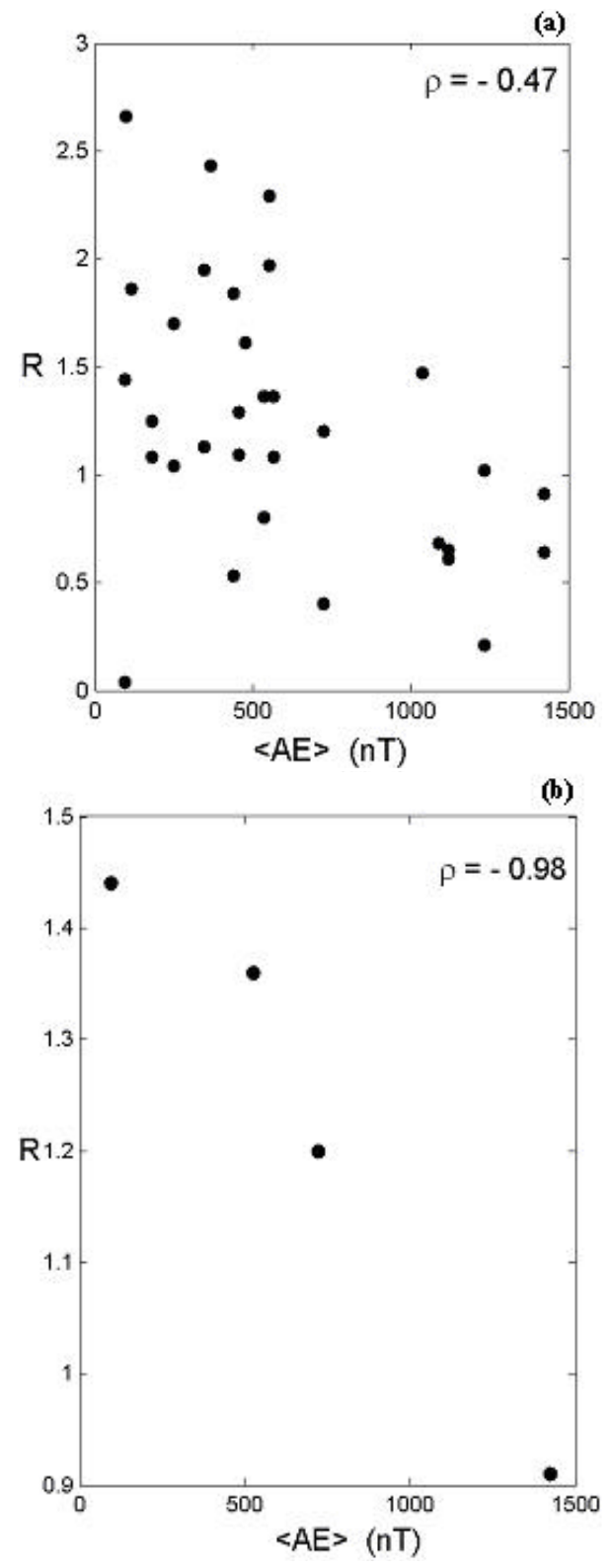

Fig. 6. The $R$-values plotted as a function of the AE index averaged over $1 \mathrm{~h}$ preceding the storm onset: (a) all the intervals, (b) only afternoon intervals during $E_{y}>8 \mathrm{mV} / \mathrm{m}$ conditions.

peaks at $\tau=-1 \mathrm{~h}$ with a very high value (the corresponding $R$-AE relationship is shown in Fig. 6b).

The relationship between $R$ and AE might be indicative of a substorm influence on the plasma sheet density in terms of density drops following the substorm occurrence. If this would be the case, high $R$-values corresponding to low AE values should be connected with high plasma sheet densities (and vice versa). Unfortunately, in the present case, simultaneous measurements of the plasma sheet density are available only in 5 cases (Fig. 7); however, despite the poor statistics, the observed values appear consistent with the proposed picture. 
Table 1. The correlation coefficient $\rho$ between $R$ and the AE index averaged over $1 \mathrm{~h}$ at different time delays $\tau$.

\begin{tabular}{rr}
\hline$\tau$ & $\rho$ \\
\hline$-3 \mathrm{~h}$ & -0.28 \\
$-2 \mathrm{~h}$ & -0.33 \\
$-1 \mathrm{~h}$ & -0.47 \\
0 & -0.31 \\
$1 \dot{\mathrm{h}}$ & -0.21 \\
$2 \mathrm{~h}$ & -0.07 \\
$3 \mathrm{~h}$ & 0.07 \\
\hline
\end{tabular}

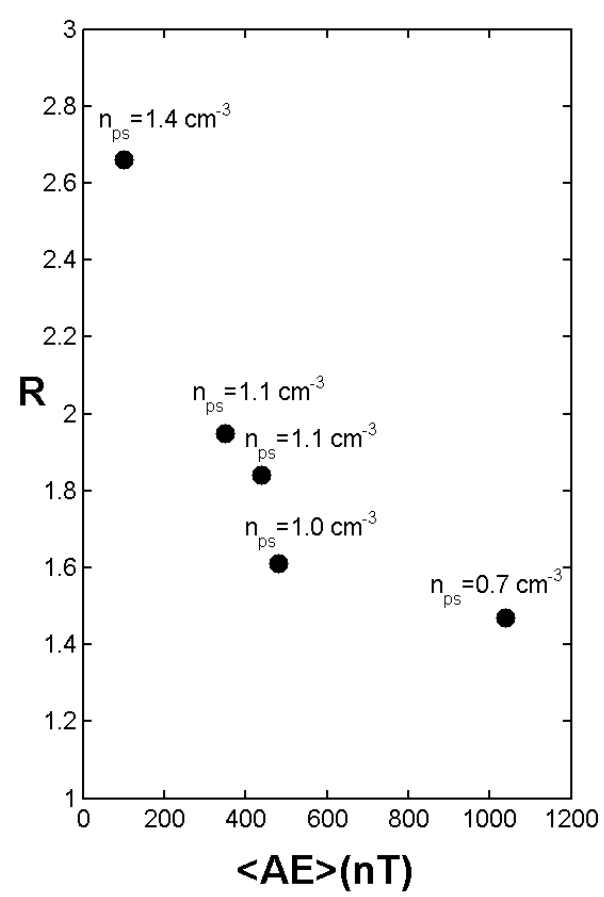

Fig. 7. The $R$-values versus the $\mathrm{AE}$ index averaged over $1 \mathrm{~h}$ preceding the storm onset for the 5 intervals for which plasma sheet density data are available (from MPA instrument on the LANL satellites orbiting geosynchronously near the geomagnetic equator). Densities of high energy ions (.13-45 keV) are indicated.

\section{Summary and discussion}

In this study we focused our attention on the asymmetry and longitudinal (or MLT) extension of the storm-time ring current by a statistical analysis of the geomagnetic field measurements at two low-latitude stations during 20 intense storms occurring between 1998-2001. We used data from two stations widely separated in MLT $(7.5 \mathrm{~h})$ to make clear that the local geomagnetic response can be different depending on the local time. Moreover, in order to evaluate the local current intensity with respect to the average current encircling the Earth, we compared the geomagnetic field component $H^{*}$ at both stations with the $D_{s t} *$ index.
Our results show that the storm-time ring current is asymmetric, extending mainly in the afternoon sector, in agreement with the results of Liemohn et al. (1999; 2001). Moreover, it emerges that the intensity of the SW electric field has an important role in determining the longitudinal extent of the storm-time ring current: indeed, during moderate SW electric field conditions, the partial ring current can also be observed in the 09:00-13:00 MLT sector. In this sense, our results suggest that stronger SW electric fields drive ions on open paths which intersect the postnoon magnetopause, preventing a complete revolution around the Earth and then producing an highly asymmetric ring current; conversely, electric fields of moderate intensity can cause closed trajectories, resulting in a more symmetric ring current: in this case, geomagnetic field disturbances can also be observed in the morning up to 09:00 MLT.

However, it is important to underline that the MLT dependence of the local current intensity with respect to the average is observed even during moderate electric field conditions; this feature suggests that the contribution from the ions on closed drift paths may also have a morning/afternoon asymmetry (Liemohn et al., 2001).

So far, the study of the complex storm-substorm relationship has been focused on the role of the substorm expansion as the driver of the ring current (Akasofu, 1968) but recently, this scenario has been questioned; the role of the magnetospheric convection, due to a stable dawn-dusk SW electric field, became important and it is proposed that substorms and storms occur as rather independent processes (McPherron, 1997; Kamide et al., 1998; Kamide, 2001). In our analysis, we investigated a possible relationship between the local ring current during the storm main phase and the substorm activity by conducting a correlation analysis between our $R$ values and the hourly averages of the AE index at different time delays $\tau$ with respect to the storm onset. We found a significant anticorrelation for $\tau=-1 \mathrm{~h}$; it indicates that, soon after a high substorm activity, a weaker ring current develops which, in the limit of the present statistics, seems to be associated with lower plasma sheet density values. This result is consistent with Kozyra (2001) observations; indeed, she found that the energization of the ring current during three storms was limited by drops in the plasma sheet density and these drops followed the occurrence of a substorm in each of the three events. In this sense, our result seems to suggest that substorms could influence indirectly the ring current formation by altering the plasma sheet conditions and can be useful in understanding what processes produce the plasma sheet variations which strongly affect the ring current dynamics (Kozyra et al., 2002).

Acknowledgements. This work was supported by a grant of the Consorzio Area di Ricerca in Astrogeofisica and by MIUR. The Memambetsu 1-min original data, $D_{s t}$ and AE indices were provided by World Data Center C2, Kyoto University. The interplanetary data from Wind were obtained through the CDAWeb key parameter database at NASA/NSSDC.

Topical Editor T. Pulkkinen thanks two referees for their help in evaluating this paper. 


\section{References}

Akasofu, S.-I.: Polar and magnetospheric substorms, D. Reidel, Dordrecht, Holland, 1968.

Borovsky, J. E., Thomsen, M. F., and Elphic, R. C.,: The driving of the plasma sheet by the solar wind, J. Geophys. Res., 103, 17 617-17 639, 1998.

Borovsky, J. E., Thomsen, M. F., and McComas, D. J.: The superdense plasma sheet: plasmaspheric origin, solar wind origin or ionospheric origin?, J. Geophys. Res., 102, 22 089-22 097, 1997.

Cahill, L. J.: Magnetosphere inflation during four magnetic storms in 1965, J. Geophys. Res., 75, 3778, 1970.

Cummings, W. D.: Asymmetric ring current and low-latitude disturbance daily variation, J. Geophys: Res., 71, 4495, 1966.

Daglis, I. A. and Kozyra, J. U.: Outstanding issues of ring current dynamics, J. Atm. Sol. Terr. Phys., 64, 253-264, 2002.

Frank, L. A.: On the extraterrestrial ring current during geomagnetic storms, J. Geophys. Res., 72, 3753, 1967.

Gonzalez, W. D., Joselyn, J. A., Kamide, Y., Kroehl, H. W., Rostoker, G., Tsurutani, B. T., and Vasyliunas, V. M.: "What is a geomagnetic storm", J. Geophys. Res., 99, 5771-5792, 1994.

Grafe, A.: Are our ideas about $D_{s t}$ correct?, Ann. Geophys., 17, 1-10, 1999.

Greenspan, M. E. and Hamilton D. C.: A test of the Dessler-ParkerSckopke relation during magnetic storms, J. Geophys. Res., 105, 5419-5430, 2000.

Hamilton, D. C., Gloeckler, G., Ipavich, F. M., Studemann, W., Wilkey, B., and Kremser, G.: Ring current development during the great geomagnetic storm of February 1986, J. Geophys. Res., 93, 14343-14355, 1988

Kamide, Y.: Interplanetary and magnetospheric electric fields during geomagnetic storms: what is more important, steady-state fields or fluctuating fields, J. Atm. Sol. Terr. Phys., 63, 413-420, 2001.

Kamide, Y., Baumjohann, W., Daglis, I. A., Gonzalez, W. D., Grande, M., Joselyn, J. A., McPherron, R. L., Phillips, J. L., Reeves, G. D., Rostoker, G., Sharma, A. S., Singer, H. J., Tsurutani, B. T., Vasyliunas, V. M.: Current understanding of magnetic storms: storm/substorm relationship, J. Geophys. Res., 103, 17 705-17 728, 1998.

Kozyra, J. U.: Storm-substorm coupling and the geoeffectiveness of intervals of southward IMF, AGU spring meeting 2001, SM41A02, 2001.

Kozyra, J. U., Jordanova, V. K., Borovsky, J. E., Thomsen, M. F., Knipp, D. J., Evans, D. S., McComas, D. J., Cayton, T. E.: Effects of high density plasma sheet on ring current development during the 2-6 November 1993 magnetic storm, J. Geophys. Res., 103, 26 285-26305, 1998.
Kozyra, J. U., Liemohn, M. W., Clauer, C. R., Ridley, A. J., Thomsen, M. F., Borovsky, J. E., Roeder, J. L., Jordanova, V. K., and Gonzalez, W. D.: Multistep $D_{s t}$ development and ring current composition changes during the 4-6 June 1991 magnetic storm, J. Geophys. Res., 107(A8), 10.1029/2001JA000023, 2002.

Liemohn, M. W., Kozyra, J. U., Jordanova, V. K., Khazanov, G. V., Thomsen, M. F., and Cayton, T. E.: Analysis of early phase ring current recovery mechanisms during geomagnetic storms, Geophys. Res. Lett., 26, 2845-2848, 1999.

Liemohn, M. W., Kozyra, J. U., Thomsen, M. F., Roeder, J. L., Lu, G., Borovsky, J. E., and Cayton, T. E.: Dominant role of the asymmetric ring current in producing the storm time $D_{s t}{ }^{*}, \mathrm{~J}$. Geophys. Res., 106, 10 883-10 904, 2001.

McPherron, R. L.: The role of the substorms in the generation of magnetic storms, in Magnetic Storms, eds.: Tsurutani, B. T., Gonzalez, W. D., Kamide, Y. and Arballo, J. Geophys. Monograph, 98, AGU, 131, 1997.

O'Brien, P. and McPherron, R. L.: Evidence against an independent solar wind density driver of the terrestrial ring current, Geophys. Res. Lett., 27, 3797-3799, 2000a.

O'Brien, P. and McPherron, R. L.: An empirical phase space analysis of ring current dynamics: solar wind control of injection and decay, J. Geophys. Res., 105, 7707-7719, 2000b.

Roelof, E. C.: Energetic neutral atom image of storm-time ring current, Geophys. Res. Lett., 14, 652-655, 1987.

Siscoe, G. L. and Crooker, N. U.: On the partial ring current contribution to $D_{s t}$, J. Geophys. Res., 79, 1110, 1974.

Skoung, R. M., Thomsen M. F., Henderson, M. G. et al.: Taildominated storm main phase: 31 March 2001, J. Geophys. Res., 108, 10.1029/2002JA009705, 2003.

Smith, J. P., Thomsen, M. F., Borovsky, J. E., and Collier, M.: Solar wind density as a driver for the ring current in mild storms, Geophys. Res. Lett., 26, 1797-1800, 1999.

Takahashi, S., Iyemori, T., and Takeda, M.: A simulation of the storm-time ring current, Planet. Space Sci., 38, 1133-1141, 1990.

Thomsen, M. F., Borovsky, J. E., Mc Comas, D. J., and Collier, M. L.: Variability of the ring current source population, Geophys. Res. Lett., 25, 3481-3484, 1998.

Tsurutani, B. T. and Gonzalez, W. D.: The interplanetary causes of magnetic storm: a review, in Magnetic Storms, Tsurutani B.T., Gonzalez, W.D. and Kamide Y. eds., AGU Monograph, Washington D.C., 77, 1997. 